\title{
Performance Study of Modified Savonius Water Turbine with Two Deflector Plates
}

\author{
Golecha Kailash, T. I. Eldho, and S. V. Prabhu \\ Department of Mechanical Engineering, Indian Institute of Technology, Powai, Mumbai 400 076, India \\ Correspondence should be addressed to S. V. Prabhu, svprabhu@me.iitb.ac.in
}

Received 12 November 2011; Accepted 13 January 2012

Academic Editor: Tariq Iqbal

Copyright ( $) 2012$ Golecha Kailash et al. This is an open access article distributed under the Creative Commons Attribution License, which permits unrestricted use, distribution, and reproduction in any medium, provided the original work is properly cited.

\begin{abstract}
Savonius rotor is a vertical axis rotor with simple in design and easy to fabricate at lower cost. The rotation of the rotor is due to the drag difference between the advancing blade and returning blade. Net driving force can be increased by reducing the reverse force on the returning blade or increasing the positive force on the advancing blade. Former can be realized by providing a flow obstacle to the returning blade and latter can be realized by concentrating the flow towards the advancing blade. The objective of the present work is to identify the optimal position of the deflector plate (on advancing blade side) placed upstream to the flow which would result in increase in power generated by the rotor. Tests are conducted to identify the optimum position of the deflector plate on the advancing blade side in the presence of a deflector plate on the returning blade side at its optimum position. Results suggest that two deflector plates placed at their optimal positions upstream to the flow increase the coefficient of power to 0.35 . This is significantly higher than the coefficient of power of 0.14 observed for the rotor without deflector plates.
\end{abstract}

\section{Introduction}

Hydropower from the river is one of the best renewable sources. Hydropower source is predictable compared to wind or solar energy. Water current turbines are zero head turbines. They generate electricity using the kinetic energy of natural water resources using different types of rotors. Usually, these rotors are fixed to a structure on the riverside or on floating pontoons. Hydrokinetic turbine electricity generation is mainly aimed for rural use at sites remote from existing electricity grids. It is a useful tool for improving the quality of life of people in these locations and for improving local economies. Different designs of water current turbine are available for the extraction of energy from the river water or canals. Based on the alignment of the rotor axis with respect to water flow, two generic classes exist. They are horizontal axis turbine (axial turbines) and vertical axis turbine (cross-flow turbines). Commonly used vertical axis turbines are Savonius turbine, helical turbine, Darrieus turbine, and $\mathrm{H}$-shaped Darrieus turbine.

Research on the water current turbines is going on worldwide. Literature suggests that water turbines are gaining popularity [1-3]. Different kinds of water turbines are being installed and tested. In the coast of Korea, GCK Technology Limited (USA) installed a Gorlov helical water turbine with a diameter of $1 \mathrm{~m}$ and height of $2.5 \mathrm{~m} \mathrm{[4].} \mathrm{Gorlov} \mathrm{vertical}$ axis water turbine has the blades of helical structure. It was proposed by Gorlov [5] to convert kinetic energy of the flowing water into electrical or mechanical energy. The advantage of this turbine is that it reduces the relative diameter of the rotor while simultaneously increasing the length of the blade. Verdant Power Limited (USA) also installed a three-bladed axial water turbine to extract the water energy from free flow in the east river New York [4]. Alternative Hydro Solutions Ltd. in Ontario has developed vertical axis turbines to extract the water energy from river [6]. New Energy Corporation Inc., with support from Natural Resources Canada and the CANMET Energy Technology Centre, is developing a series of turbine/generator sets that produce between $5 \mathrm{~kW}$ and $25 \mathrm{~kW}$ of power and can be used in rivers, irrigation canals, industrial outflows, and tidal estuaries. The turbines are of vertical axis water turbines [7].

Majority of the turbines installed in Ireland and developed to extract the tidal and marine current energy are 


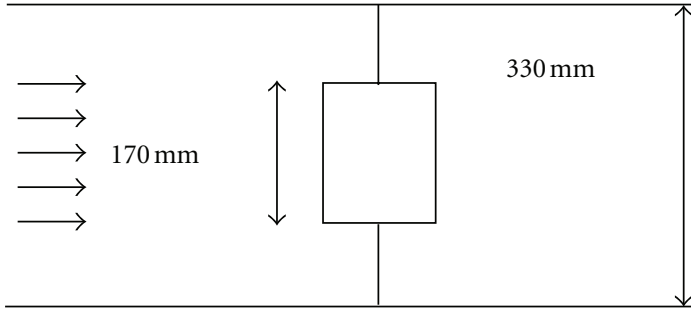

(a)

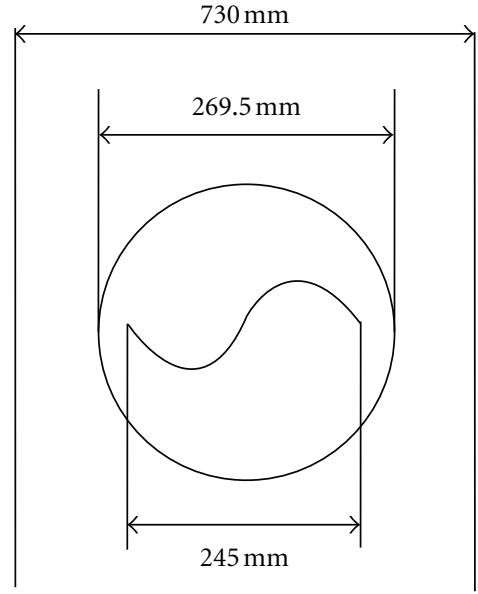

(b)

Figure 1: (a) Side view of the experimental setup and channel. (b) Top view of the experimental set-up channel.

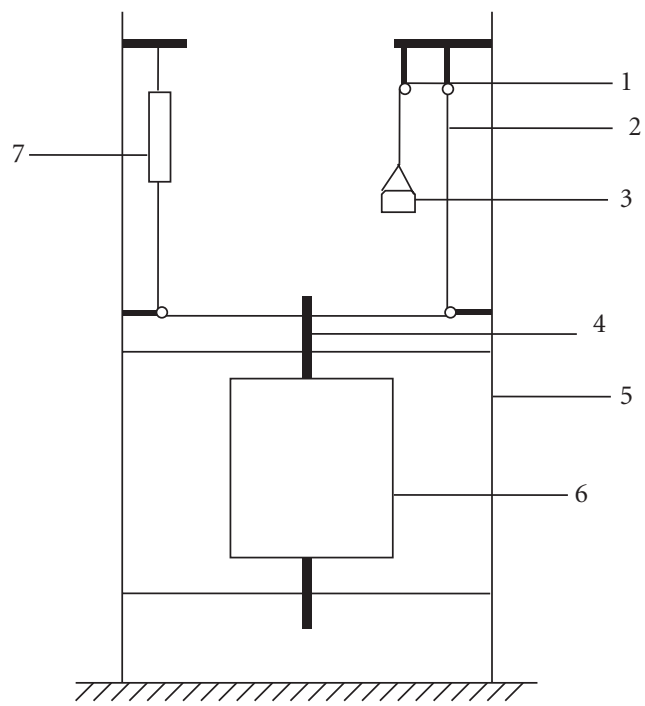

(1) Pulley

(2) Nylon string $1 \mathrm{~mm}$ diameter

(3) Weighing pan

(4) Shaft
(5) Supporting structure

(6) Savonius rotor

(7) Spring balance

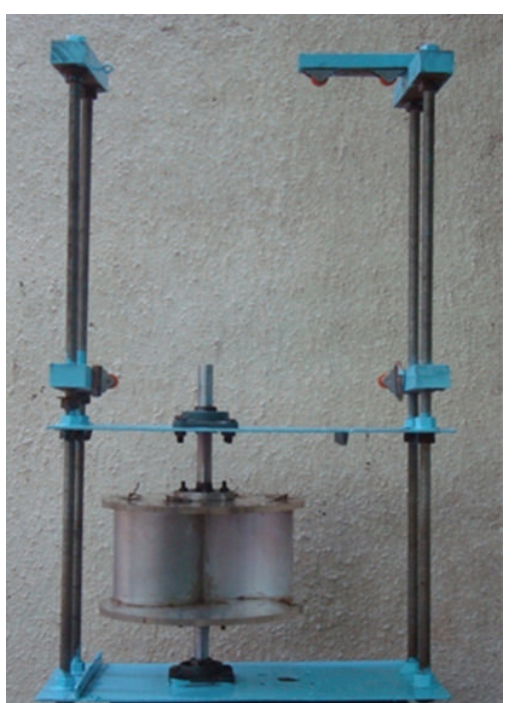

(b)

FIGURE 2: (a) Schematic diagram of the test setup for modified Savonius rotor, (b) pictorial representation of test setup for modified Savonius rotor.

of horizontal axis water current turbine [8]. The designs of these turbines are similar to the modern day wind turbines as structural point of view. Vertical axis turbines like Darrieus, Savonius, and Gorlov helical are used for free flow applications to extract the energy from river, irrigation canal, and industrial flows. Results reported by Gorlov [5] suggested that maximum coefficient of power of helical turbine is around 0.35 . Savonius turbines are drag-type devices as drag force is the main driving force for this type machine. Savonius rotor is simple in design and construction, but still not as popular as compare to the horizontal axis water turbine due to its poor performance. Table 1 shows the summary of investigations on the Savonius turbine with water as working medium. Khan et al. [9] tested the single-stage, two-stage and three-stage conventional Savonius turbine in a water channel. They reported a maximum coefficient of power of $0.038,0.049$, and 0.04 for singlestage, two-stage, and three-stage Savonius turbines, respectively. Nakajima et al. [10] investigated the conventional Savonius turbine with a horizontal axis in a water channel. They concluded that the maximum coefficient of power is 0.25 at a Reynolds number of $1.1 \times 10^{5}$. However, tunnel 
TABLE 1: Summary of experimental investigation carried out by researchers on Savonius turbines with water as working medium.

\begin{tabular}{|c|c|c|c|c|c|c|c|c|}
\hline Author & $\begin{array}{c}\text { Turbine } \\
\text { aspect ratio } \\
(H / D)\end{array}$ & $\begin{array}{l}\text { Reynolds } \\
\text { number } \\
\times 10^{5}\end{array}$ & $\begin{array}{l}\text { Free stream } \\
\text { velocity } \\
(\mathrm{m} / \mathrm{s})\end{array}$ & $\begin{array}{l}\text { Water tunnel } \\
\text { dimensions } \\
(\mathrm{m} \times \mathrm{m})\end{array}$ & $\begin{array}{l}\text { Orientation } \\
\text { of the axis }\end{array}$ & Turbines tested & $\begin{array}{c}\text { Parameters } \\
\text { measured }\end{array}$ & Results \\
\hline $\begin{array}{l}\text { Khan } \\
\text { et al. [9] }\end{array}$ & 1.82 & $\begin{array}{l}0.98 \\
1.52 \\
1.96\end{array}$ & 1 & $5 \times 3$ & Vertical & $\begin{array}{l}\text { Single-stage, } \\
\text { two-stage, three-stage } \\
\text { conventional Savonius } \\
\text { turbines with an } \\
\text { overlap ratio of } 0.207\end{array}$ & $C p, C t$ & $\begin{array}{l}C p_{\max } \text { of } 0.038,0.049 \text {, and } \\
0.04 \text { for single-, two-, and } \\
\text { three-stage Savonius } \\
\text { turbines }\end{array}$ \\
\hline $\begin{array}{l}\text { Nakajima } \\
\text { et al. [10] }\end{array}$ & 1.48 & 1.1 & 0.8 & $0.6 \times 0.5$ & Horizontal & $\begin{array}{l}\text { Single-stage } \\
\text { conventional Savonius } \\
\text { turbine }\end{array}$ & $\begin{array}{c}C p, \text { flow } \\
\text { visualisation }\end{array}$ & $\begin{array}{l}C p_{\max } \text { of } 0.25 \text { for } \\
\text { single-stage Savonius } \\
\text { turbine }\end{array}$ \\
\hline $\begin{array}{l}\text { Nakajima } \\
\text { et al. [11] }\end{array}$ & $1.2,2.4$ & 1.1 & 0.8 & $0.6 \times 0.5$ & Horizontal & $\begin{array}{l}\text { Single-stage and } \\
\text { two-stage conventional } \\
\text { Savonius turbine with } \\
\text { an overlap ratio of } 0.36\end{array}$ & $\begin{array}{c}C p, \text { flow } \\
\text { visualisation }\end{array}$ & $\begin{array}{l}C p_{\max } \text { of } 0.275 \text { for } \\
\text { two-stage with } 90^{\circ} \text { phase } \\
\text { shift compared to } 0.25 \text { for } \\
\text { single-stage turbine and } \\
\text { flow visualisation gives the } \\
\text { torque generation } \\
\text { mechanism }\end{array}$ \\
\hline $\begin{array}{l}\text { Golecha } \\
\text { et al. [12] }\end{array}$ & 0.70 & 1.32 & 0.45 & $0.73 \times 0.33$ & Vertical & $\begin{array}{l}\text { Single-stage, two-stage } \\
\text { and three-stage } \\
\text { modified Savonius } \\
\text { turbine with and } \\
\text { without deflector plate }\end{array}$ & $C p, C t$ & $\begin{array}{l}50 \% \text { improvement in the } \\
C p_{\max } \text { for single-stage } \\
\text { modified Savonius with } \\
\text { deflector plate at optimal } \\
\text { position }\end{array}$ \\
\hline
\end{tabular}

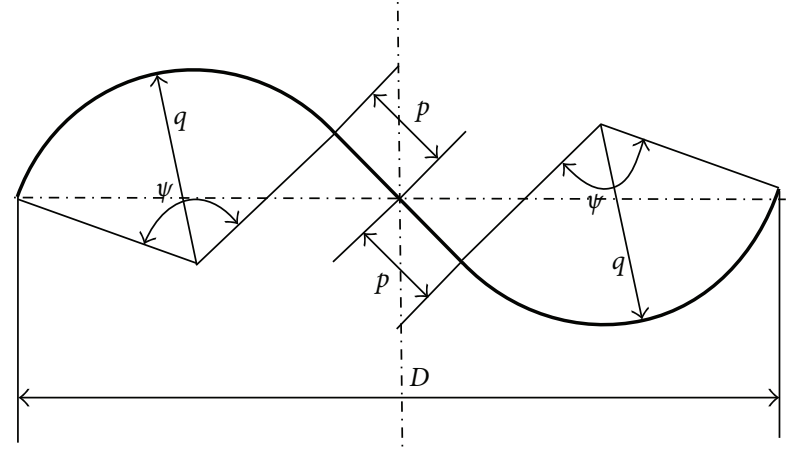

FIgure 3: Top view of modified Savonius rotor without shaft in between the end plates [18].

interference is not considered in their study. Nakajima et al. [11] investigated three different types of models (single stage and double stage with $0^{\circ}$ and $90^{\circ}$ phase shift). Flow field around the turbine is examined visually to reveal the enhancement mechanisms of power coefficient using the double stage turbine. Results indicate that $90^{\circ}$ phase difference in the blades improve the power coefficient by about $10 \%$ at maximum ( 0.275 compared to 0.25 for single stage turbine). Golecha et al. [12] carried out an experimental investigation on the performance improvement of the modified Savonius rotor by providing a deflector plate on the returning blade side. Appropriate position of the deflector plate is identified in their study for the maximum coefficient of power. Results conclude that the deflector plate at its optimal position increases the coefficient of the power by $50 \%$ for a single-stage modified Savonius rotor.

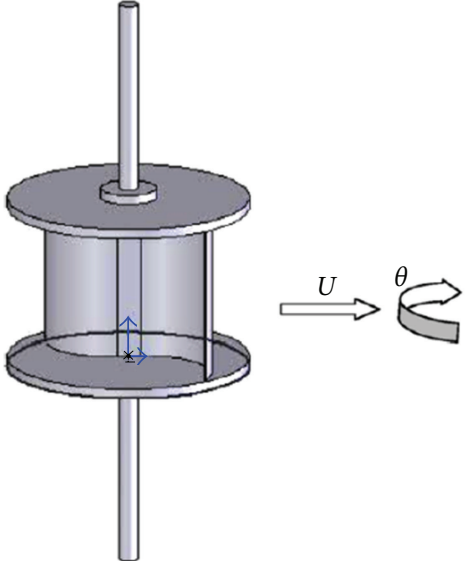

(a)

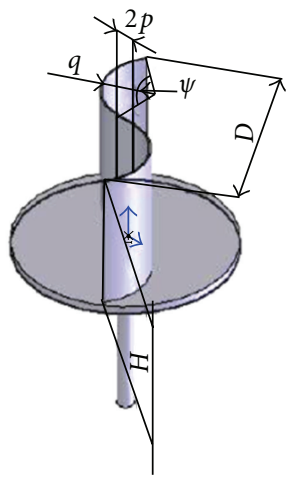

(b)

FIgUre 4: (a) Modified Savonius rotor without shaft in between end plates. (b) Geometrical parameters of modified Savonius rotor [18].

They reported that maximum coefficient of power improves by $42 \%, 31 \%$, and $17 \%$ with deflector plate for two-stage $0^{\circ}$ phase shift, $90^{\circ}$ phase shift, and three-stage modified Savonius rotor, respectively.

Various techniques adopted by many researchers to increase the performance and improve the starting torque characteristics of Savonius turbine were with wind as working medium. These techniques include use of guide vanes [13], V-block deflector [14], partially blocked Savonius rotor [15], deflector plate [16], and blade with flat and circular shielding [17]. Details of these investigations are given in tabular form by Golecha et al. [12]. Some of these techniques 
require change in the design of blade, and others involve supplementary devices in addition to the existing system. Performance of the rotor can be improved by reducing the fluid resistance encountered by the convex surface of the returning blade or increasing the drag on the concave surface of the advancing blade. Both the techniques will increase the resultant drag acting on the rotor improving the power output. The former is done by shielding the returning blade with deflector plate, and the latter can be realized by concentrating the flow towards the advancing blade by placing a deflector plate on the advancing blade side. Flow concentrated by the deflector plate towards the advancing blade increases the rotational speed of the rotor. This is due to the fact that water striking on concave surface of the advancing blade is at a higher velocity compared to the free stream velocity. This results in the increase in the output power of the rotor. Hence, deflector plates are more effective in water channels because of the fixed direction of the fluid.

Experimental investigations are carried out by Kamoji et al. [18] on the performance of modified form of conventional rotor (modified Savonius rotor) with and without central shaft between the end plates. Rotors with different overlap ratios $G(a / 2 R)$, blade arc angles, and aspect ratios were studied for different Reynolds numbers $\left(0.8 \times 10^{5}, 1 \times 10^{5}, 1.2 \times\right.$ $10^{5}$, and $\left.1.5 \times 10^{5}\right)$. Results concluded that the modified (without central shaft) Savonius rotor with an overlap ratio of 0.0 , a blade arc angle of $124^{\circ}$, and an aspect ratio of 0.7 resulted in a $C p_{\max }$ of 0.21 at a Reynolds number of 150000 . This is higher than that of conventional Savonius rotor (0.19). Correlation is developed for a single-stage modified Savonius rotor for a range of Reynolds numbers studied.

Literature survey suggests that there is reasonable improvement in the performance of modified Savonius rotor with a deflector plate on the returning blade side. However, there is no information available on the improvement of the rotor performance by proper placement of deflector plate on the advancing blade side. Hence, an experimental investigation is conducted to identify the appropriate position of the deflector plate on the advancing blade side to increase the coefficient of power of the rotor. Optimal configuration of the deflector plate on the returning blade side is taken from the Golecha et al. [12]. Best configuration of modified Savonius rotor (without shaft) is considered for the present work [18].

\section{Experimental Setup and Procedure}

Figure 1 shows schematic the water channel used for present study, and Figure 2 shows the experimental setup for conducting tests on rotating Savonius rotor. The setup consists of a structure housing the modified Savonius rotor fabricated using studs and mild steel plates. The mild steel plates are held in place by means of washers and nuts. Two bearings (UC 204, NTN make) bolted to the mild steel plates support the Savonius rotor. The usage of studs, nuts, and bolts facilitated easy replacement of rotors of different diameters and positioning of rotor centre at the centre of the water channel. A brake drum dynamometer is used for loading the Savonius
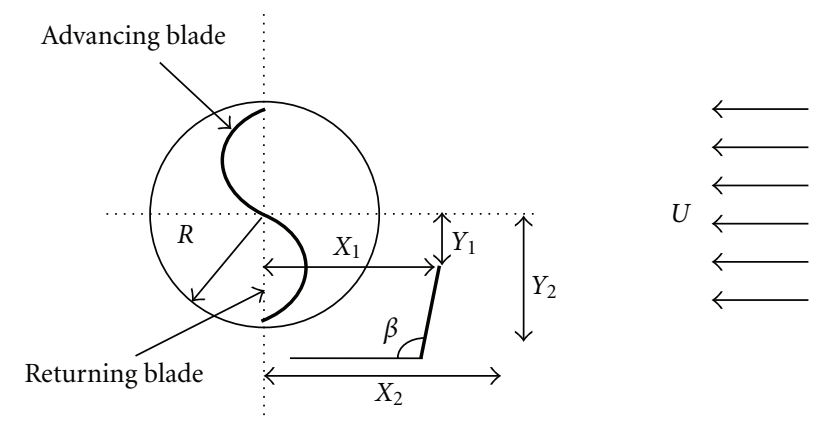

FIGURE 5: Schematic of modified Savonius rotor with geometrical parameters of deflector plate [12].

rotor. The weighing pan, pulley, and spring balance (Salter make, accuracy of $2.5 \mathrm{gms}$ ) are connected by a nylon string of $1 \mathrm{~mm}$ diameter. Friction is an important parameter that affects the measurement of torque of the rotating Savonius rotor. Friction in the bearings and the $1 \mathrm{~mm}$ inelastic fishing nylon wire wound on the rotor shaft must be minimized. The seals are removed from the bearings, and bearings are washed in petrol to remove the grease before mounting resulting in the reduction of friction. Lubricant WD 40 is also used to reduce the friction in the bearings. The rotor is loaded gradually to record spring balance reading, weights, and rotational speed of the rotor. For each load, rotation speed $(N)$ is calculated 3 times, and this is done for the purpose of getting the maximum possible accuracy in the results.

The experimental setup is placed in an open channel having a cross-sectional area of $730 \mathrm{~mm} \times 330 \mathrm{~mm}$. The water in the channel is supplied by a 40 H.P. centrifugal pump through a $203 \mathrm{~mm}$ diameter pipe which is recirculated back. Discharge in the channel is measured by venturi meter having a coefficient of discharge of 0.99 and area ratio of 0.6 . Differential pressure transducer (APT model 3100, Duon make) is used for pressure drop measurement across venturi meter.

\section{Single-Stage Modified Savonius Rotor}

Kamoji et al. [18] conducted the experiments on modified Savonius rotors with varying overlap ratios $G$, aspect ratio $(H / D)$, blade arc angle $(\Psi)$, and blade shape factor $(p / q)$. They determined the better rotor configuration of the singlestage modified Savonius rotor (without shaft in between the end plates) corresponding to maximum coefficient of power. The geometrical parameters for optimum rotor configuration are $H / D=0.7, \Psi=124^{\circ}, p / q=0.2$ with a zero overlap ratio. The diameter and height of the rotor are $245 \mathrm{~mm}$ and $170 \mathrm{~mm}$, respectively, in the present study. The end plate diameter $\left(D_{o}\right)$ is kept constant at $1.1 D$. The deflector plates are made of mild steel having $2 \mathrm{~mm}$ thickness.

Figures 3 and 4 show the basic modified Savonius rotor without shaft used in the present study and the isometric view of the modified Savonius rotor [18]. Modified Savonius rotor is fabricated from aluminum pipe. The thickness of the aluminum blade is $2 \mathrm{~mm}$. The rotors are covered at the top 


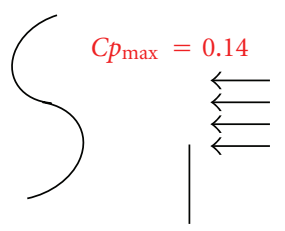

1

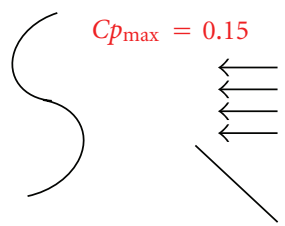

4

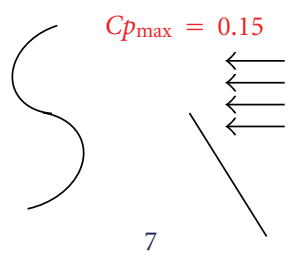

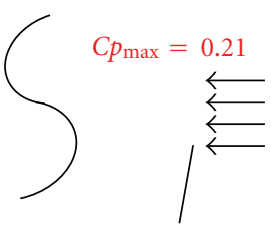

2
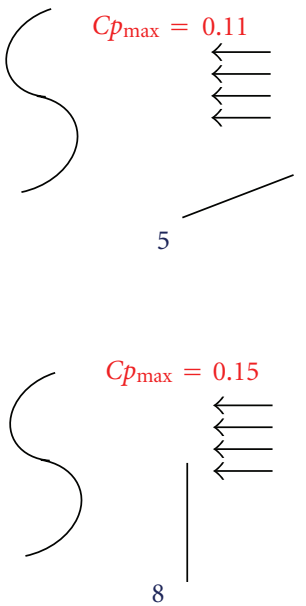

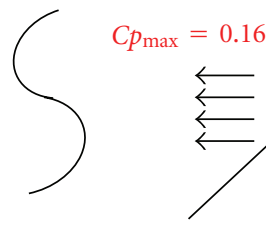

3
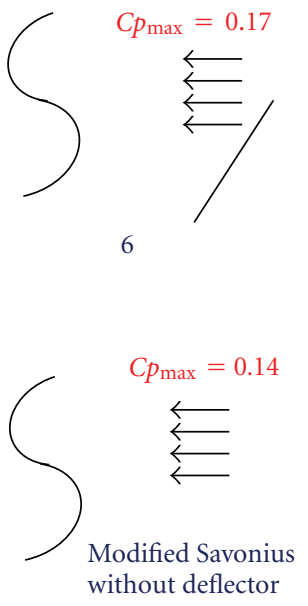

Figure 6: Different positioning of deflector plate on the returning blade side with respect to modified Savonius rotor and corresponding $C p_{\max }[12]$.
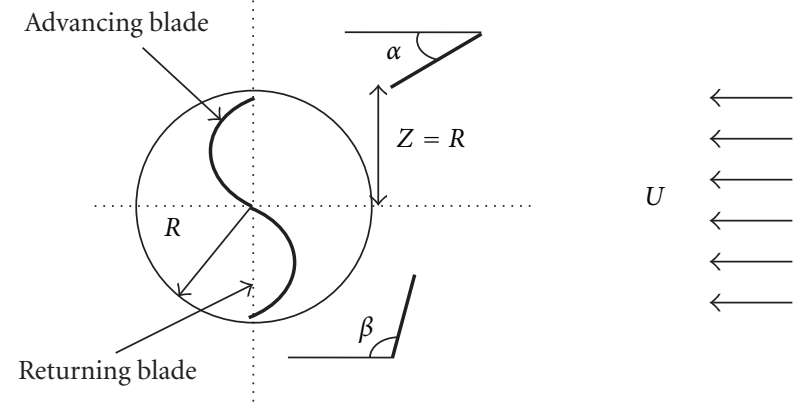

FIGURE 7: Schematic of modified Savonius rotor with space parameters of two deflector plate $(Z=R)$.

and bottom by an acrylic plate of $10 \mathrm{~mm}$ thickness. Modified Savonius rotor without shaft is not having any shaft bolted to the two acrylic sheets.

\section{Optimization of Deflector Plate Position on the Advancing Blade Side}

Investigations carried out by Golecha et al. [12] with single deflector plate on returning blade side shows that the maximum coefficient of power increases to 0.21 at a tip speed ratio 0.82 for optimal configuration 2 . The geometrical parameters $\left(X_{1}=152 \mathrm{~mm}, X_{2}=135 \mathrm{~mm}, Y_{1}=55 \mathrm{~mm}\right.$, and $\beta=101^{\circ}$ ) for deflector plate corresponding to this configuration are optimum as represent in Figure 5. Pictorial

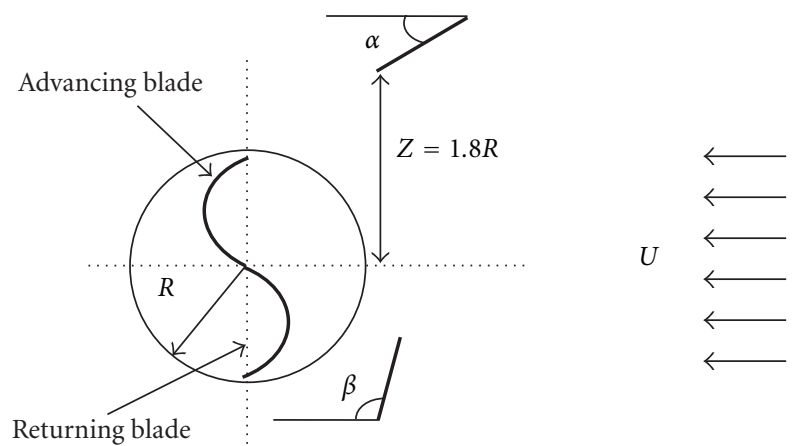

FIGURE 8: Schematic of modified Savonius rotor with space parameters of two deflector plate $(Z=1.8 R)$.

representation of all the configurations investigated in their study and corresponding $C p_{\max }$ is shown in Figure 6 [12]. In the presence of deflector plate at optimal position on the returning blade side, one more deflector plate is placed on the advancing blade side in the present study. The purpose of deflector plate on the advancing side is usually to augment the rotational speed or the output power of the rotor. The position of the deflector plate on the advancing blade side is varied to identify the position which yields maximum coefficient of power. Figures 7 and 8 show the modified Savonius rotor with two deflector plate. Eight different configurations are studied with varying deflector plate angles $(\alpha)$ as well as distance between the rotor center $(Z)$ and the top tip of deflector plate on the advancing blade 

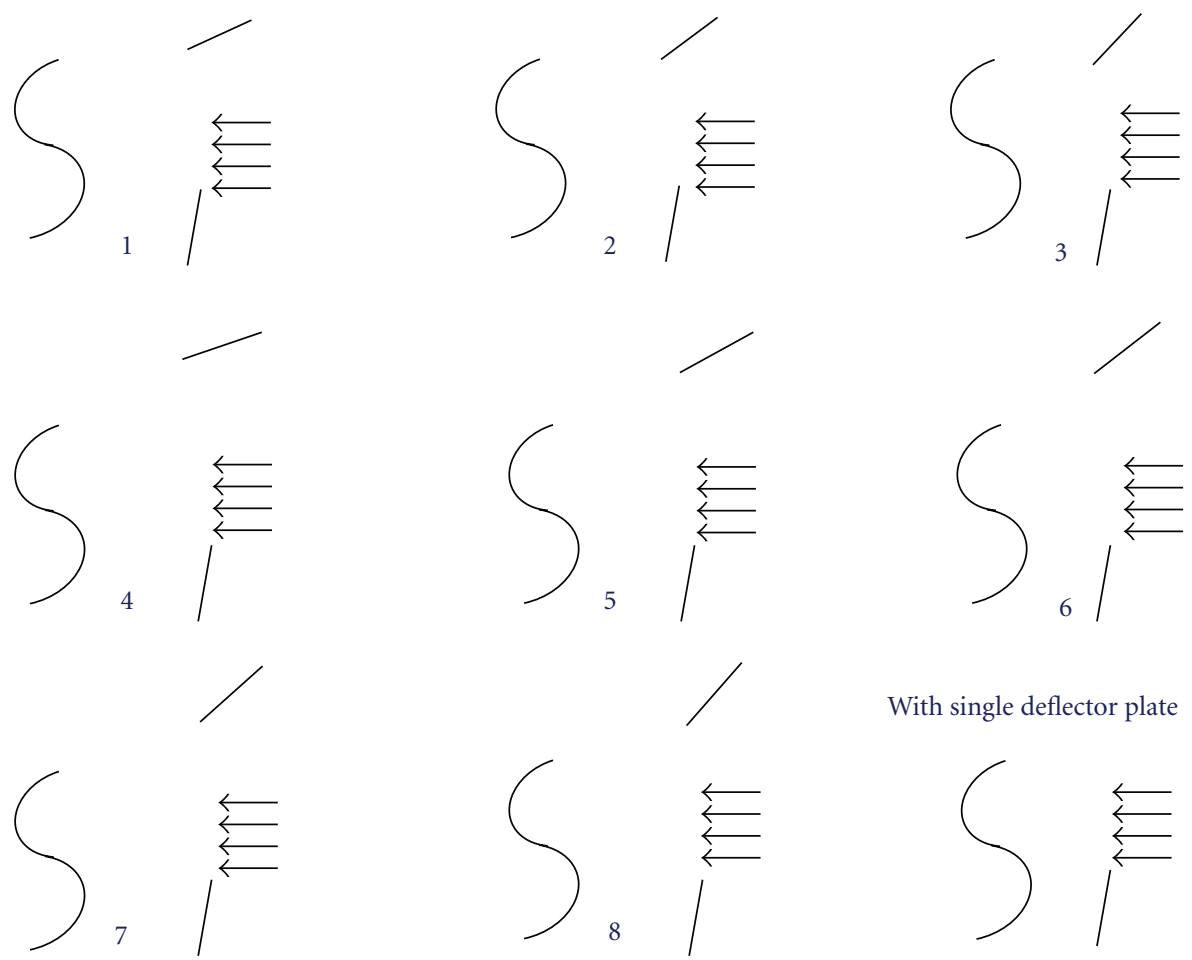

With single deflector plate
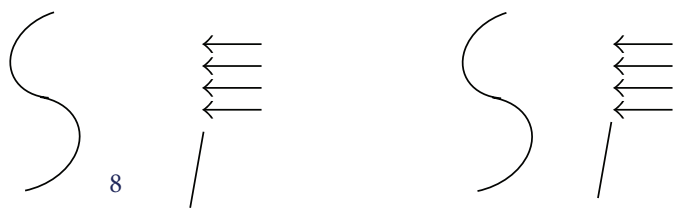

FIGURE 9: Different arrangements of the two deflector plates studied in the present study with the deflector plate on the returning blade side is at its optimum position.

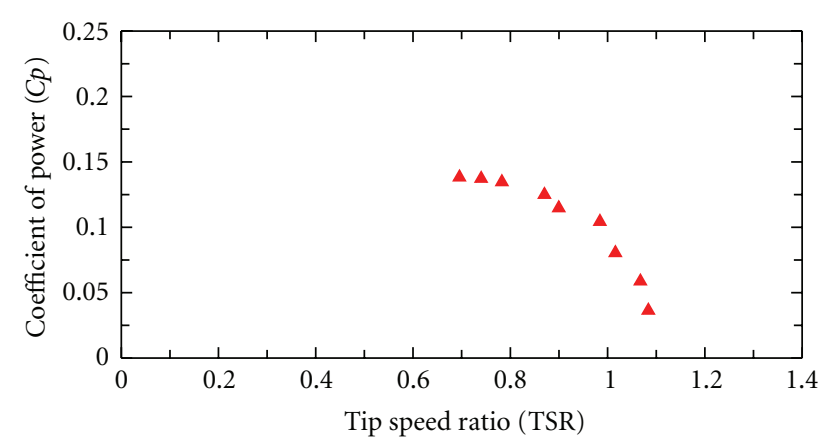

(a)

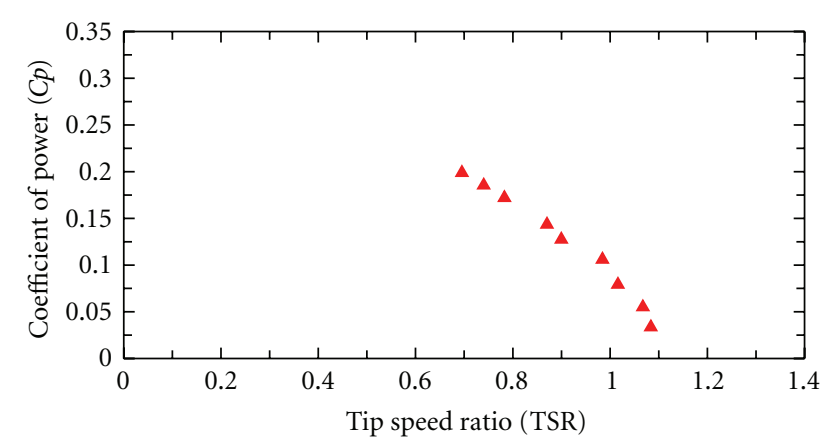

- Modified Savonius (without deflector)

(b)

FIGURE 10: Variation of coefficient of power and coefficient of torque with respect to tip speed ratio for modified Savonius without deflector.
TABLe 2: Geometrical parameters for deflector plate positioning on the advancing blade side.

\begin{tabular}{lcc}
\hline Configuration number & $\begin{array}{c}\text { Distance from } \\
\text { rotor center }(Z)\end{array}$ & $\begin{array}{c}\text { Angle from the } \\
\text { horizontal axis }(\alpha)\end{array}$ \\
\hline 1 & $R$ & $15^{\circ}$ \\
2 & $R$ & $30^{\circ}$ \\
3 & $R$ & $45^{\circ}$ \\
4 & $1.8 R$ & $20^{\circ}$ \\
5 & $1.8 R$ & $30^{\circ}$ \\
6 & $1.8 R$ & $40^{\circ}$ \\
7 & $1.8 R$ & $50^{\circ}$ \\
8 & $1.8 R$ & $60^{\circ}$ \\
\hline
\end{tabular}

side. Pictorial depiction is given in Figure 8 for different arrangement. Table 2 gives the dimensional details for all the configurations studied. Two distances $R$ and $1.8 R$ are taken from the rotor center and top tip of deflector plate (as shown in Figures 7 and 8). Figure 9 shows the pictorial representation of the different arrangements of two deflector plates with modified Savonius rotor.

\section{Data Reduction}

Reynolds number based on the rotor diameter is given by

$$
\operatorname{Re}=\frac{\rho U D}{\mu},
$$



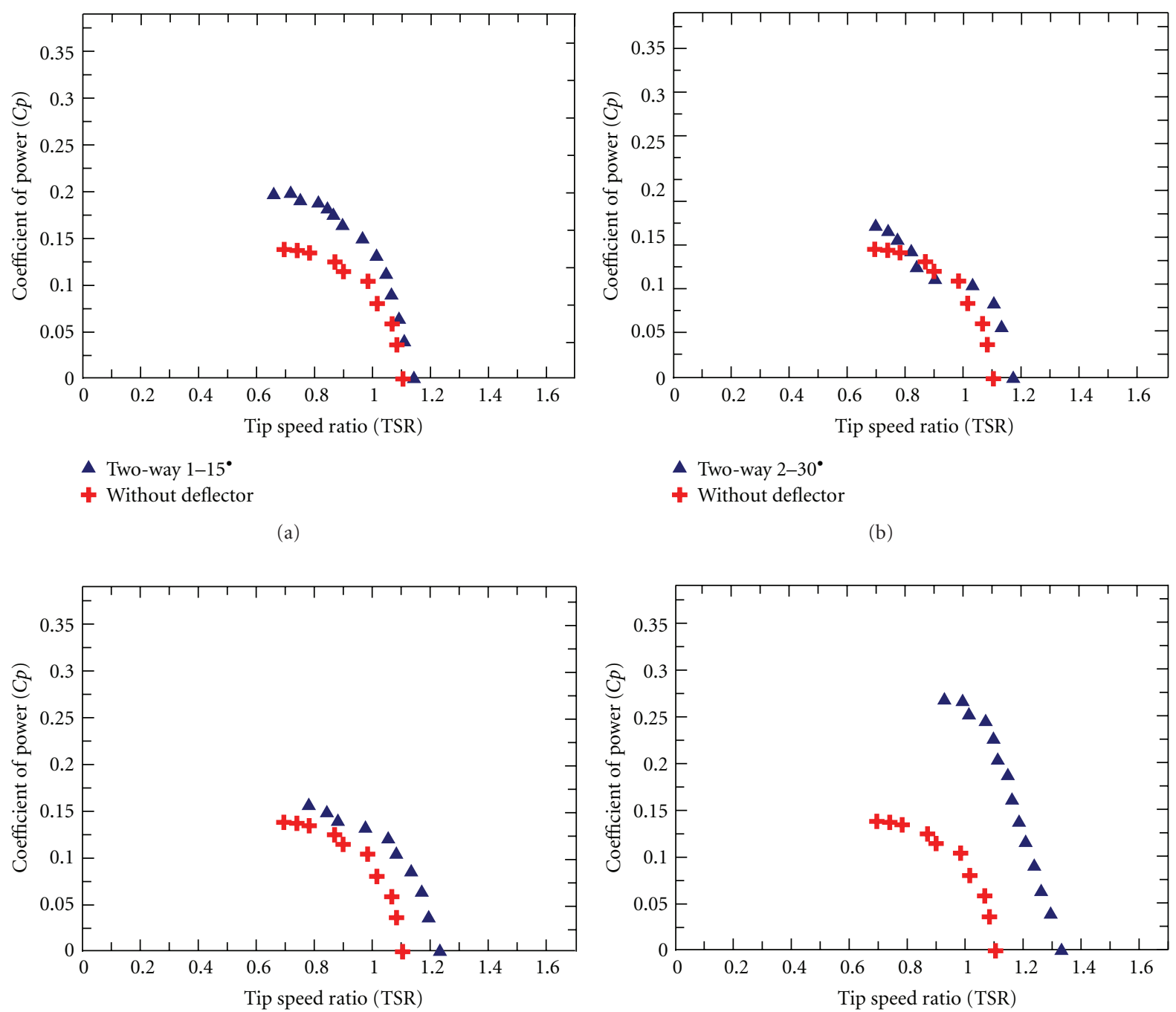

A Two-way 4-20

+ Without deflector

(d)

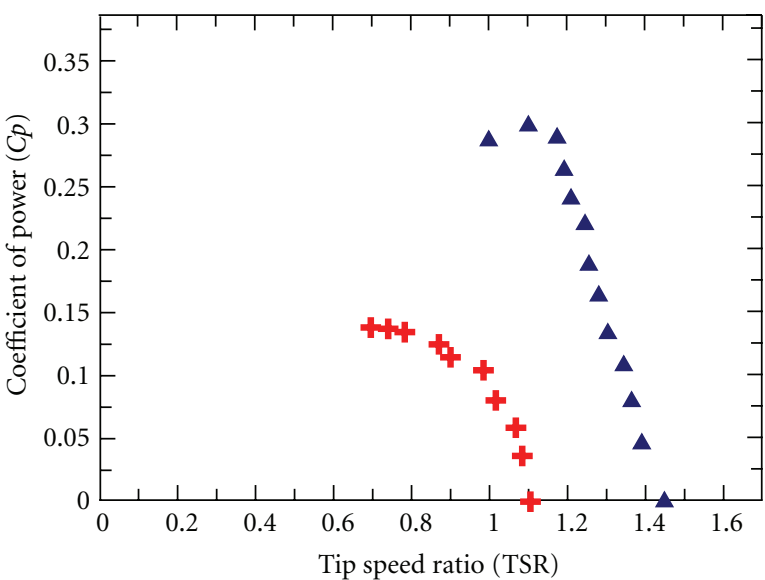

$\Delta$ Two-way 6-40

+ Without deflector (a)

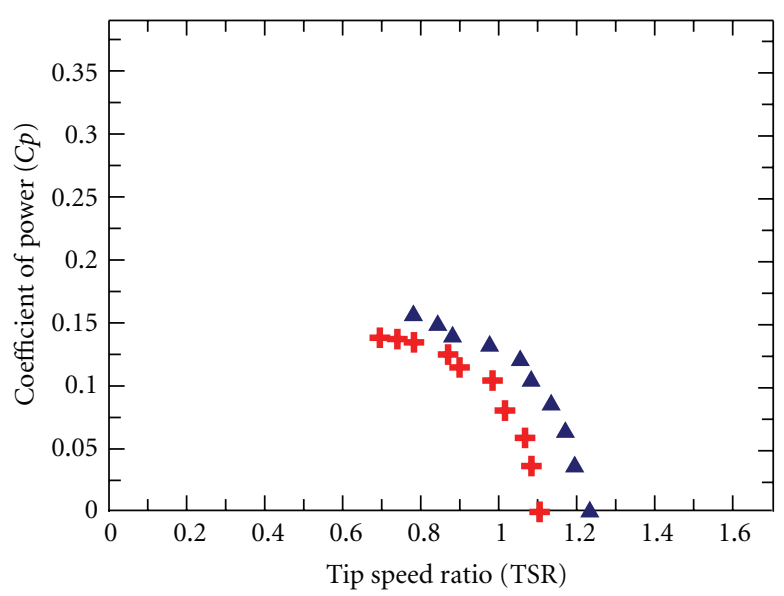

$\Delta$ Two-way $3-45^{\circ}$

+ Without deflector

(b)

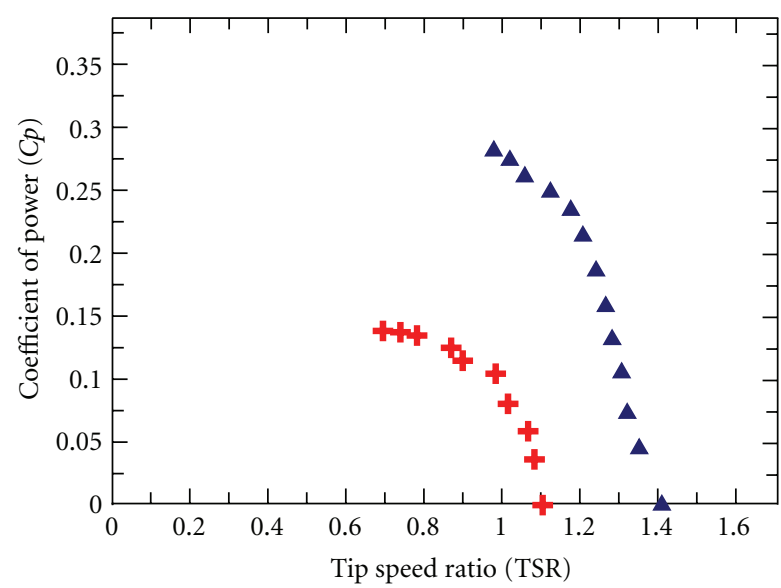

- Two-way 5-30

+ Without deflector

(e) 


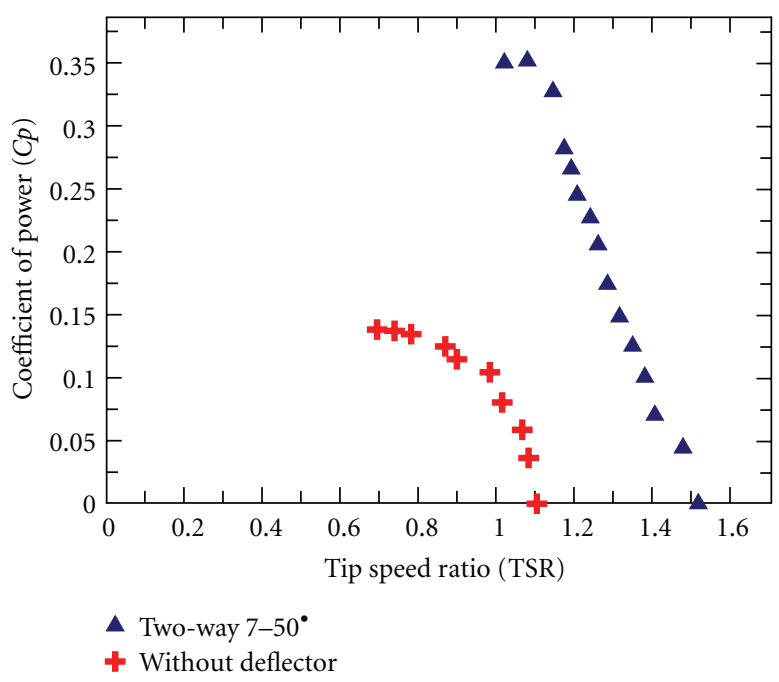

(g)

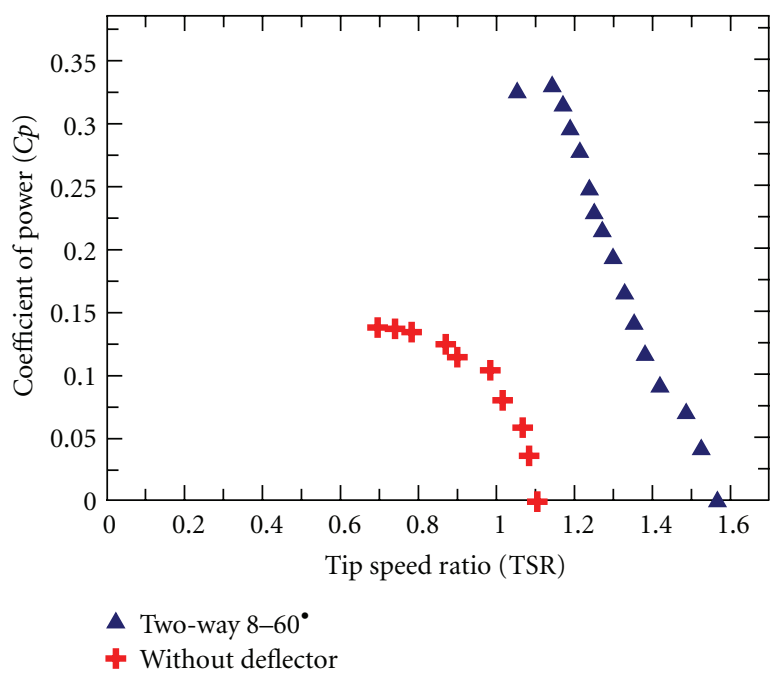

(h)

FIgURE 11: Variation of coefficient of power with TSR for modified Savonius rotor with and without two deflector plates.

where Re is Reynolds number, $\rho$ is the density of water, $U$ is the free stream velocity, $D$ is the rotor diameter, and $\mu$ is the absolute viscosity of water.

Tip speed ratio is given by

$$
\operatorname{TSR}=\frac{\omega D}{2 U},
$$

where $\omega$ is the angular velocity.

Torque is calculated from the measured load, and spring balance load is given by

$$
T=\frac{(M-S)\left(r_{\text {shaft }}+d_{r}\right) g}{1000},
$$

where $M$ is the load, $S$ is spring balance load, $r_{\text {shaft }}$ is the radius of the shaft, $d_{r}$ is the diameter of the nylon string.

Coefficient of torque $(C t)$, and coefficients of power $(C p)$ are given by

$$
\begin{aligned}
& C t=\frac{4 T}{\rho U^{2} D^{2} H}, \\
& C p=\mathrm{TSR} \times C t .
\end{aligned}
$$

Blockage ratio is given by

$$
\text { blockage ratio }=B=\frac{H D}{H_{w} W},
$$

where $H_{w}$ is the height of the water channel and $W$ is the width of the water channel. In the present study, the blockage ratio for modified Savonius rotors is around 15\%.

Uncertainties in various basic parameters, tip speed ratio, coefficient of torque, and coefficient of power at the maximum coefficient of power are around $2.5 \%, 4.5 \%$, and $4.8 \%$, respectively. Uncertainty calculations are carried out based on Moffat [19].

\section{Results and Discussions}

Experiments are conducted in an open water channel at a Reynolds number of $1.32 \times 10^{5}$. Tests are conducted on single-stage modified Savonius rotor, and optimum design parameters for the rotor are taken from Kamoji et al. [18]. Experiments are conducted to determine the coefficient of power and coefficient of torque for the different configurations of deflector plate positioning on the advancing blade side. Figure 10 shows the variation of coefficient of power and coefficient of torque with respect to tip speed ratio for modified Savonius rotor without deflector plate tested in present study. The maximum coefficient of power of 0.14 at a tip speed ratio of 0.7 is observed. Maximum coefficient of torque corresponding to tip ratio at maximum coefficient of power is of 0.2. Test results show on the right half of the $C p$-TSR and $C t$-TSR curve because experimental procedure involves the increasing load on the turbine incrementally from no load condition for a fixed free-stream velocity of the water in the channel. Under no load condition, the rotational speed of the turbine would be maximum. As the load is increased, the rotational speed of the turbine decreases. Hence, tip speed ratio decreases. For a certain load, the turbine cannot rotate because it cannot generate torque as it is overloaded. This is the reason that there are no or very few data points on the left-half part of the curve. Deflector plate placed upstream to the fluid flow on the returning blade side acts as an obstacle to the flow coming towards the returning blade. This reduces the negative or reverse torque on the returning blade. Maximum coefficient of power of 0.21 at a tip speed ratio 0.82 is reported for deflector plate at its optimal position on returning blade side [12].

By placing the deflector plate on the returning blade side at its optimal position, experiments are conducted for different positions of the deflector plate on the advancing 


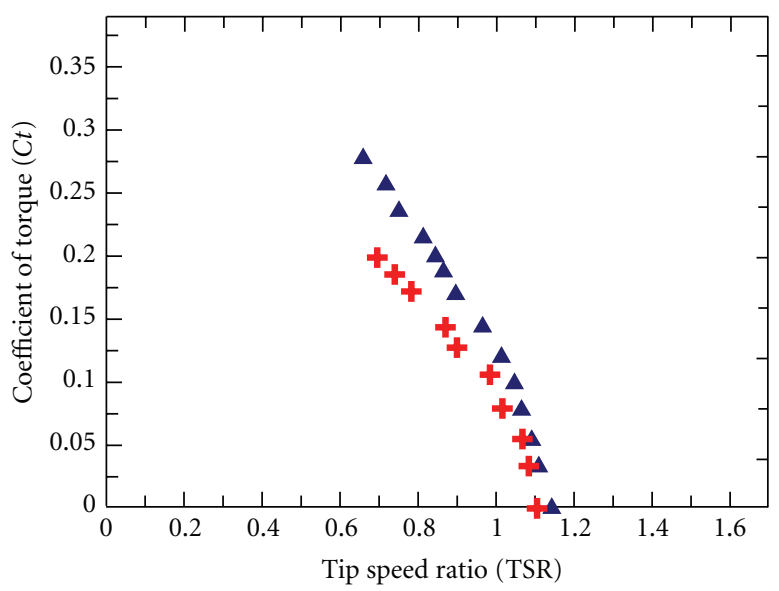

$\Delta$ Two-way $1-15^{\circ}$

+ Without deflector

(a)

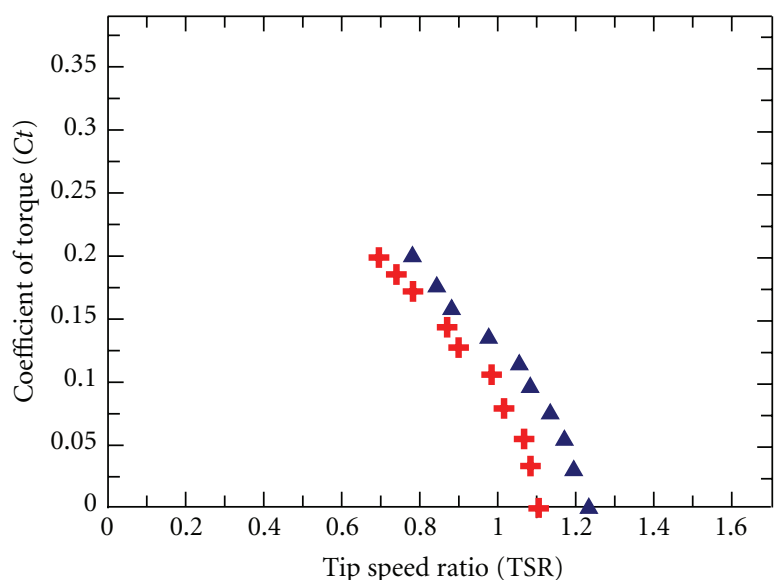

- Two-way $3-45^{\circ}$

+ Without deflector

(c)

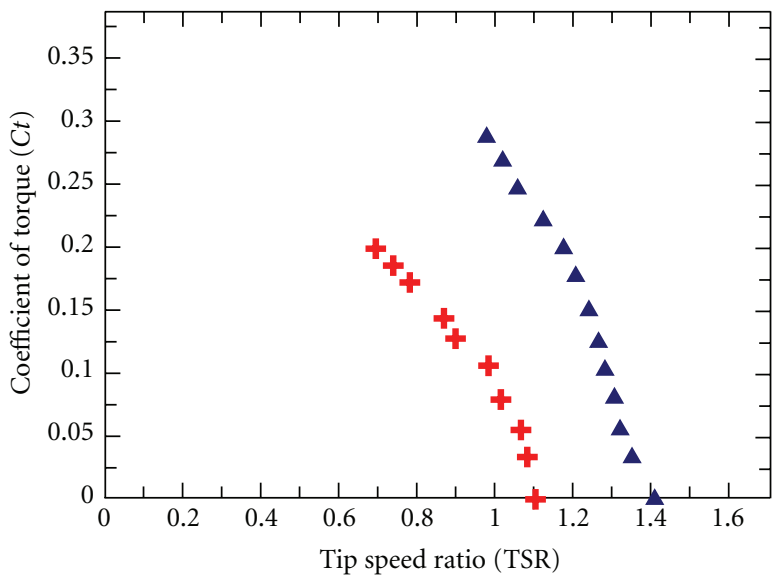

$\Delta$ Two-way 5-30

+ Without deflector

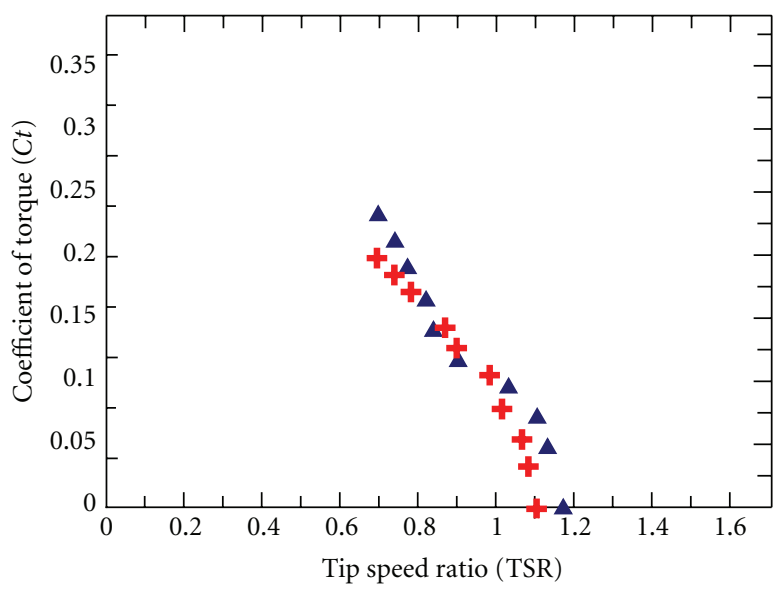

- Two-way 2-30

+ Without deflector

(b)

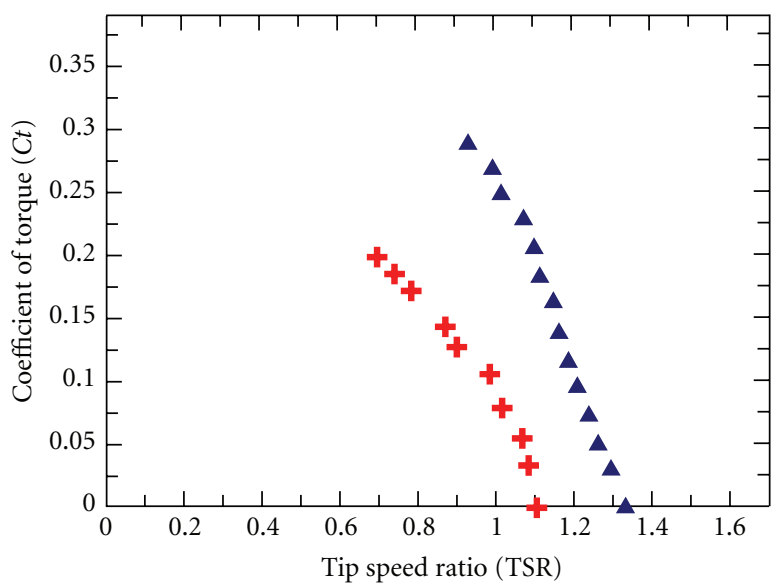

- Two-way 4-20

+ Without deflector

(d)

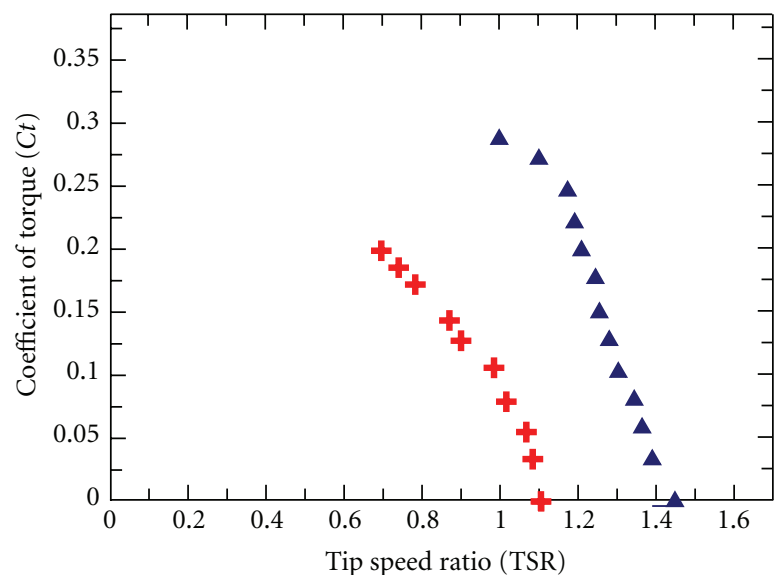

A Two-way $6-40^{\circ}$

+ Without deflector

(e) 


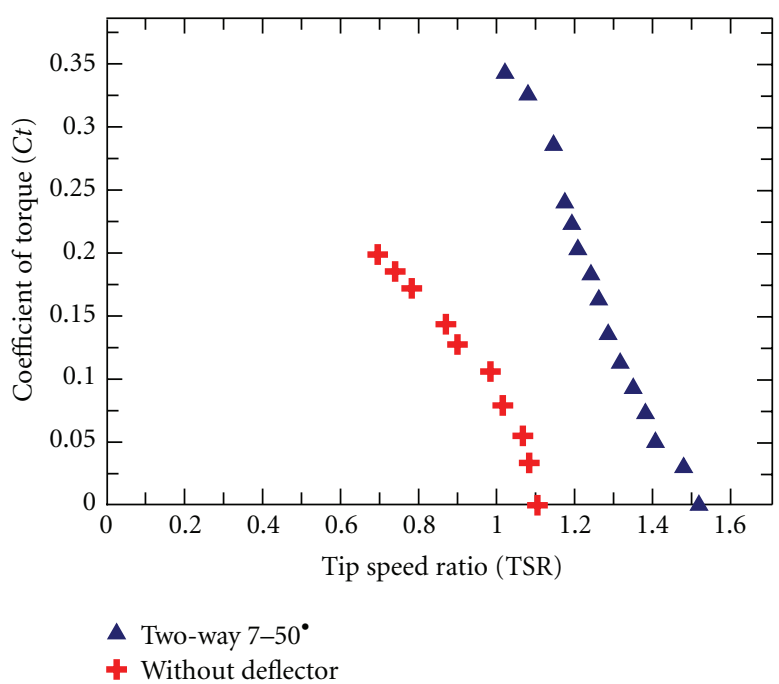

(g)

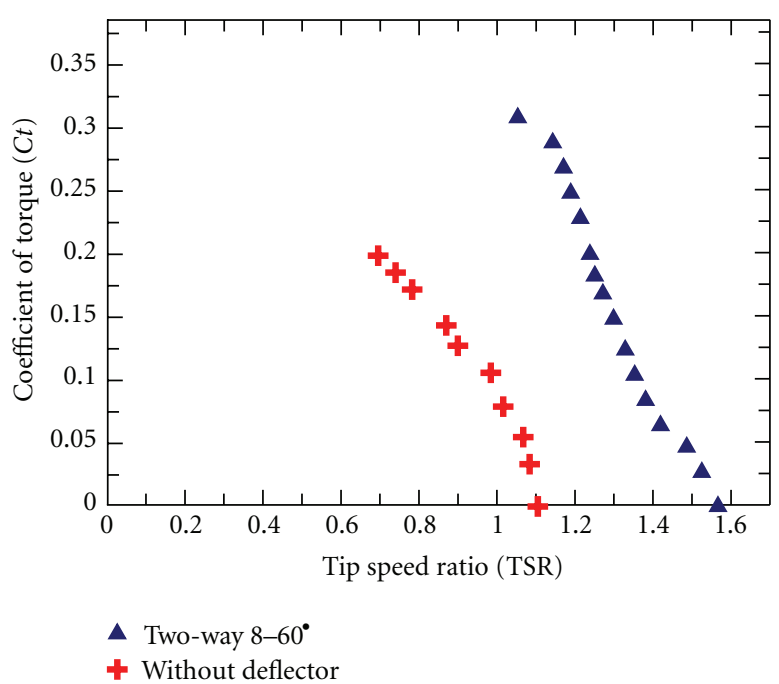

(h)

FIGURE 12: Variation of coefficient of torque with TSR for modified Savonius rotor with and without two deflector plate.

TABLE 3: Maximum coefficient of power and the corresponding tip speed ratio and coefficient of torque for the configuration studied on the two deflector plates.

\begin{tabular}{lccc}
\hline $\begin{array}{l}\text { Configuration } \\
\text { number }\end{array}$ & $\begin{array}{c}\text { Maximum } \\
\text { coefficient of } \\
\text { power } C p_{\max }\end{array}$ & $\begin{array}{c}\text { Tip speed ratio } \\
\text { corresponding } \\
\text { to } C p_{\max }\end{array}$ & $\begin{array}{c}\text { Maximum } \\
\text { coefficient of } \\
\text { torque at } C p_{\max }\end{array}$ \\
\hline 1 & 0.20 & 0.72 & 0.26 \\
2 & 0.16 & 0.70 & 0.23 \\
3 & 0.15 & 0.78 & 0.20 \\
4 & 0.27 & 0.93 & 0.29 \\
5 & 0.28 & 0.98 & 0.29 \\
6 & 0.30 & 1.01 & 0.27 \\
7 & $\mathbf{0 . 3 5}$ & $\mathbf{1 . 1 0}$ & $\mathbf{0 . 3 2}$ \\
8 & 0.33 & 1.14 & 0.29 \\
\hline
\end{tabular}

blade side of modified Savonius rotor. Optimum configuration of deflector plate on the returning blade side is taken from Golecha et al. [12]. Experiments are carried out with different arrangements of deflector plate on advancing blade side at different plate angles $(\alpha)$ and the distance from the rotor center $(Z)$. Figures 11 and 12 show the variation of the coefficient of power and coefficient of torque for the different arrangements of the two deflector plate. Table 3 gives the maximum coefficient of power along with the corresponding tip speed ratio and coefficient of torque for the two deflector plate arrangement studied. The maximum coefficient of power is obtained with deflector plate arrangement 7 , so arrangement 7 is determined as the optimum deflector plate arrangement under given conditions. Optimum position of the deflector plate is found at a deflector plate angle $(\alpha)$ of $50^{\circ}$ and $Z=1.8 R$.

In general, deflector plate placed at $1.8 R$ from the rotor centre experiences higher coefficient of power compared to
TABle 4: $C p_{\max }$ and corresponding TSR and $C t$ of modified Savonius rotors with and without deflector plate.

\begin{tabular}{lcccc}
\hline Modified Savonius rotor & $\begin{array}{c}\text { Aspect ratio } \\
(H / D)\end{array}$ & $C p_{\max }$ & $\begin{array}{c}\text { TSR at } \\
C p_{\max }\end{array}$ & $\begin{array}{c}C t \text { at } \\
C p_{\max }\end{array}$ \\
\hline $\begin{array}{l}\text { Without deflector plate } \\
\begin{array}{l}\text { With optimum deflector } \\
\text { plate on returning blade side }\end{array}\end{array}$ & 0.7 & 0.14 & 0.70 & 0.20 \\
$\begin{array}{l}\text { With optimum two deflector } \\
\text { plates }\end{array}$ & 0.7 & 0.21 & 0.82 & 0.26 \\
\hline
\end{tabular}

that placed at $R$. As flow acceleration towards advancing blade increases the positive torque on the concave surface of the advancing blade. However, this flow acceleration causes negative torque on the convex surface of the returning blade. This effect becomes more pronounced for the deflector plate placed nearer the rotor center. For the deflector plate placed at a distance of $R$ from the rotor center, coefficient of power decreases with the increase in the deflector plate angle $(\alpha)$ from $15^{\circ}$ to $45^{\circ}$. As the deflector plate angle increases from $15^{\circ}$ to $45^{\circ}$, the flow is streaming towards the returning blade which is detrimental for the performance of the rotor. For the deflector plate placed at a distance of $1.8 R$ from the rotor center, coefficient of power increases with the increase of deflector plate angle up to $50^{\circ}$. This may be because of the proper streaming of the flow towards the advancing blade for higher deflector plate angles.

Figure 13 shows the variation of coefficient of power and coefficient of torque with TSR for the rotor without deflector plates, rotor with single deflector plate, and the rotor with two deflector plates at their optimal positions. Comparison of coefficient of power and coefficient of torque for the modified Savonius rotor with and without deflector plates is given in Table 4. The coefficient of power and coefficient of torque improve significantly for the optimum deflector 


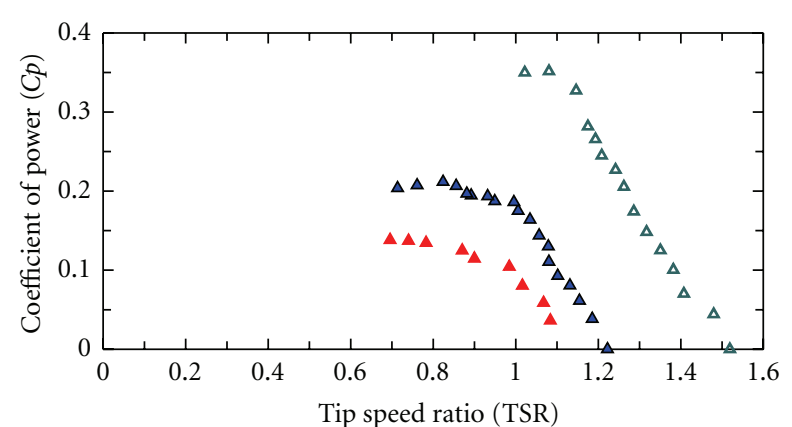

(a)

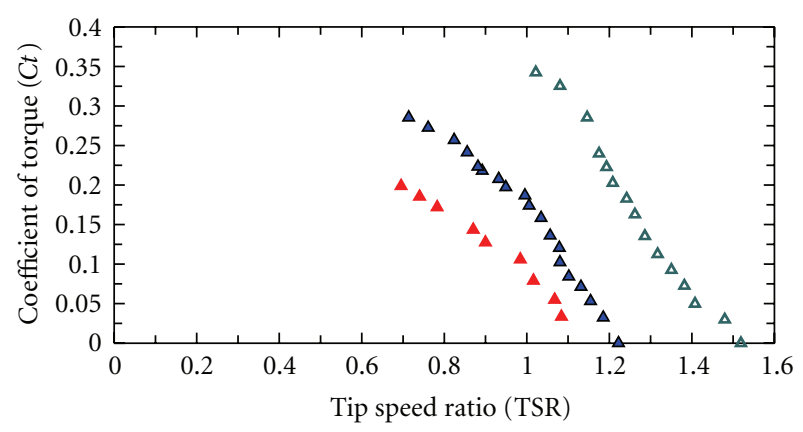

\ Modified Savonius (without deflector)

$\Delta$ Optimum deflector on returning blade side

$\Delta$ Optimal position of two deflectors

(b)

FIGURE 13: Comparison of coefficient of power and coefficient of torque with TSR for modified Savonius rotor with and without single and two deflector plates.

plate arrangement with the modified Savonius rotor. Maximum coefficient of power for the modified Savonius rotor increases to 0.35 with the two deflector plates placed at their optimal positions. Figure 14 shows the pictorial representation of single and two deflector plates at their optimal positions.

\section{Conclusions}

Modified Savonius rotor is modification of the blade shape in the conventional Savonius rotor. Its blade consists of circular arc followed by straight instead of fully semicircular for conventional Savonius rotor and has higher coefficient of power. In the present study, an experimental investigation is conducted on single-stage modified Savonius rotor in an open water channel at a Reynolds number of $1.32 \times 10^{5}$ based on the diameter of the rotor. Maximum coefficient of power of single-stage modified Savonius rotor is 0.14 at a tip speed ratio of 0.7 without deflector plate. Placing the deflector plate on the returning blade side improves the coefficient of power of the modified Savonius rotor to 0.21 at a tip speed ratio of 0.82 . Deflector plate on the advancing blade side is placed at different positions in an effort to identify an appropriate position which experiences maximum coefficient of power of modified Savonius rotor with a deflector plate on the returning blade side. Maximum coefficient of power with deflector plates on the advancing blade side and returning blade side significantly improves to 0.35 at a tip speed of 1.08 . Present study shows the promise of using deflector plates on both advancing blade side and returning blade side to increase the performance of the modified Savonius rotor.

\section{Nomenclature}

\begin{tabular}{|c|c|}
\hline$a:$ & Overlap distance (mm) \\
\hline$B:$ & Blockage ratio, $\left(H D / H_{w} W\right)$ \\
\hline$C p:$ & Coefficient of power, $\left(2 T \omega / \rho U^{3} D H\right)$ \\
\hline$C p_{\max }:$ & $\begin{array}{l}\text { Maximum coefficient of power, } \\
\left(2 T \omega / \rho U^{3} D H\right)\end{array}$ \\
\hline$C t:$ & Coefficient of torque, $\left(4 T / \rho U^{2} D^{2} H\right)$ \\
\hline$d_{r}:$ & Diameter of nylon string $(\mathrm{mm})$ \\
\hline$D:$ & Rotor diameter, $(\mathrm{mm})$ \\
\hline$D_{o}:$ & End plate diameter, $(\mathrm{mm})$ \\
\hline$G:$ & Overlap ratio, $a / 2 R$ \\
\hline$H:$ & Rotor height, (mm) \\
\hline$H_{w}:$ & Height of the water channel (mm) \\
\hline$M:$ & Load (gram) \\
\hline$N:$ & Rotational speed, (rpm) \\
\hline$p:$ & $\begin{array}{l}\text { Straight edge of blade for modified Savonius } \\
\text { rotor, }(\mathrm{mm})\end{array}$ \\
\hline$q:$ & $\begin{array}{l}\text { Radius of circular arc for modified Savonius } \\
\text { rotor, }(\mathrm{mm})\end{array}$ \\
\hline$R:$ & Bucket or blade radius, (mm) \\
\hline Re: & Reynolds number, $(\rho U D / \mu)$ \\
\hline$r_{\text {shaft }}:$ & Radius of shaft (mm) \\
\hline$S:$ & Spring balance load (gram) \\
\hline$T:$ & Torque $(\mathrm{N}-\mathrm{m})$ \\
\hline TSR: & Tip speed ratio, $(\omega D /(2 U))$ \\
\hline$U:$ & Free stream velocity, $(\mathrm{m} / \mathrm{s})$ \\
\hline$W:$ & Width of the water channel $(\mathrm{mm})$ \\
\hline$X_{1}:$ & $\begin{array}{l}\text { Horizontal distance between the rotor centre } \\
\text { to the upper tip of deflector plate }(\mathrm{mm})\end{array}$ \\
\hline$X_{2}$ & $\begin{array}{l}\text { Horizontal distance between the rotor centre } \\
\text { to the bottom tip of deflector plate }(\mathrm{mm})\end{array}$ \\
\hline$Y_{1}:$ & $\begin{array}{l}\text { Vertical distance between the rotor centre to } \\
\text { the upper tip of deflector plate }(\mathrm{mm})\end{array}$ \\
\hline$Y_{2}:$ & $\begin{array}{l}\text { Vertical distance between the rotor centre to } \\
\text { the bottom tip of deflector plate }(\mathrm{mm})\end{array}$ \\
\hline$Z:$ & $\begin{array}{l}\text { Vertical distance between the rotor center } \\
\text { and the top tip of deflector plate on the } \\
\text { advancing blade side }(\mathrm{mm}) \text {. }\end{array}$ \\
\hline
\end{tabular}

\section{Greek Symbols}

$\alpha, \beta$ : Angle made by the deflecting plate with the horizontal axis, (rad)

$\mu$ : $\quad$ Absolute viscosity of the water, (Pa.s)

$\rho$ : Density of the water, $\left(\mathrm{kg} / \mathrm{m}^{3}\right)$ 


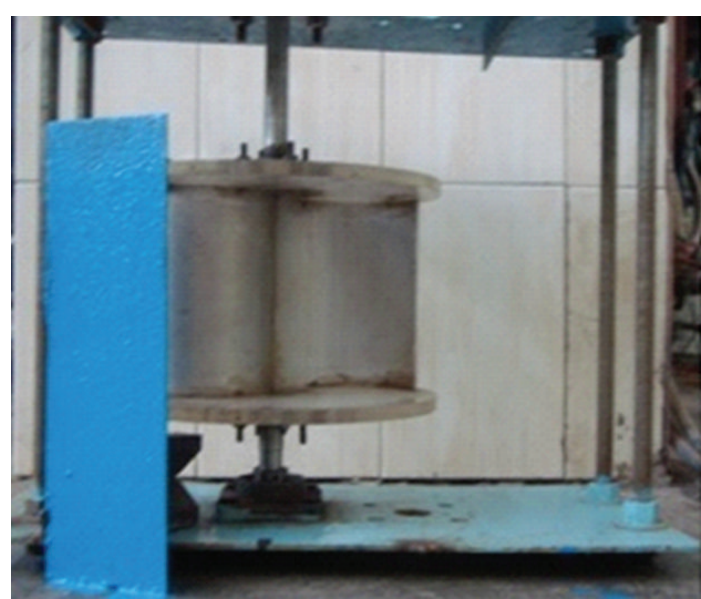

(a)

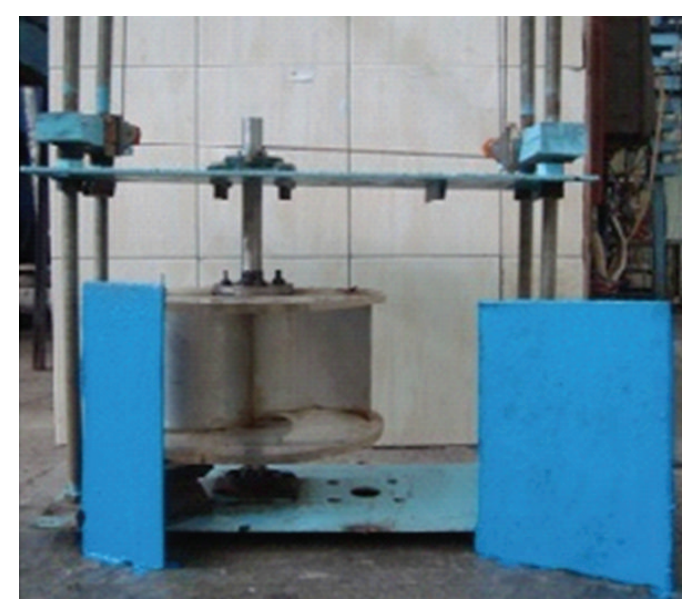

(b)

Figure 14: Pictorial representation of the modified Savonius rotor with deflector plate on the returning blade side (a) and rotor with two deflector plates (b).

$\omega$ : Angular velocity of the rotor, $(\mathrm{rad} / \mathrm{s})$

$\psi$ : Blade arc angle for modified Savonius rotor,

(rad).

\section{References}

[1] M. J. Khan, G. Bhuyan, M. T. Iqbal, and J. E. Quaicoe, "Hydrokinetic energy conversion systems and assessment of horizontal and vertical axis turbines for river and tidal applications: a technology status review," Applied Energy, vol. 86, no. 10, pp. 1823-1835, 2009.

[2] M. Anyi and B. Kirke, "Evaluation of small axial flow hydrokinetic turbines for remote communities," Energy for Sustainable Development, vol. 14, no. 2, pp. 110-116, 2010.

[3] M. S. Güney and K. Kaygusuz, "Hydrokinetic energy conversion systems: a technology status review," Renewable and Sustainable Energy Reviews, vol. 14, no. 9, pp. X2996-3004, 2010.

[4] F. O. Rourke, F. Boyle, and A. Reynolds, "Marine current energy devices: current status and possible future applications in Ireland," Renewable and Sustainable Energy Reviews, vol. 14, no. 3, pp. 1026-1036, 2010.

[5] A. M. Gorlov, "Helical turbines for the gulf stream: conceptual approach to design of a large-scale floating power farm," Marine Technology, vol. 35, no. 3, pp. 175-182, 1998.

[6] M. J. Khan, M. T. Iqbal, and J. E. Quaicoe, "River current energy conversion systems: progress, prospects and challenges," Renewable and Sustainable Energy Reviews, vol. 12, no. 8, pp. 2177-2193, 2008.

[7] V. Ginter and C. Bear, "Development and application of a water current turbine," New Energy Corporation Inc., 2009, http://www.newenergycorp.ca/.

[8] F. O. Rourke, F. Boyle, and A. Reynolds, "Renewable energy resources and technologies applicable to Ireland," Renewable and Sustainable Energy Reviews, vol. 13, no. 8, pp. 1975-1984, 2009.

[9] M. N. I. Khan, M. Tariq Iqbal, M. Hinchey, and V. Masek, "Performance of savonius rotor as a water current turbine," Journal of Ocean Technology, vol. 4, no. 2, pp. 71-83, 2009.

[10] M. Nakajima, S. Iio, and T. Ikeda, "Performance of Savonius rotor for environment friendly hydraulic turbine," Journal of Fluid Science and Technology, vol. 3, no. 3, pp. 420-429, 2008.
[11] M. Nakajima, S. Iio, and T. Ikeda, "Performance of double step Savonius rotor for environmentally friendly hydraulic turbine," Journal of Fluid Science and Technology, vol. 3, no. 3, pp. 410-419, 2008.

[12] K. Golecha, T. I. Eldho, and S. V. Prabhu, "Influence of the deflector plate on the performance of modified Savonius water turbine," Applied Energy, vol. 88, no. 9, pp. 3207-3217, 2011.

[13] T. Hayashi, Y. Li, and Y. Hara, "Wind tunnel tests on a different phase three-stage Savonius rotor," JSME International Journal, Series B, vol. 48, no. 1, pp. 9-16, 2005.

[14] B. M. Shaughnessy and S. D. Probert, "Partially-blocked savonius rotor," Applied Energy, vol. 43, no. 4, pp. 239-249, 1992.

[15] M. D. Huda, M. A. Selim, A. K. M. S. Islam, and M. Q. Islam, "Performance of an S-shaped savonius rotor with a deflecting plate," RERIC International Energy Journal, vol. 14, no. 1, pp. 25-32, 1992.

[16] T. Ogawa, H. Yoshida, and Y. Yokota, "Development of rotational speed control systems for a Savonius-type wind turbine," Journal of Fluids Engineering, Transactions of the ASME, vol. 111, no. 1, pp. 53-58, 1989.

[17] A. J. Alexander and B. P. Holownia, "Wind tunnel tests on a savonius rotor," Journal of Industrial Aerodynamics, vol. 3, no. 4, pp. 343-351, 1978.

[18] M. A. Kamoji, S. B. Kedare, and S. V. Prabhu, "Experimental investigations on single stage modified Savonius rotor," Applied Energy, vol. 86, no. 7-8, pp. 1064-1073, 2009.

[19] R. J. Moffat, "Describing the uncertainties in experimental results," Experimental Thermal and Fluid Science, vol. 1, no. 1, pp. 3-17, 1988. 

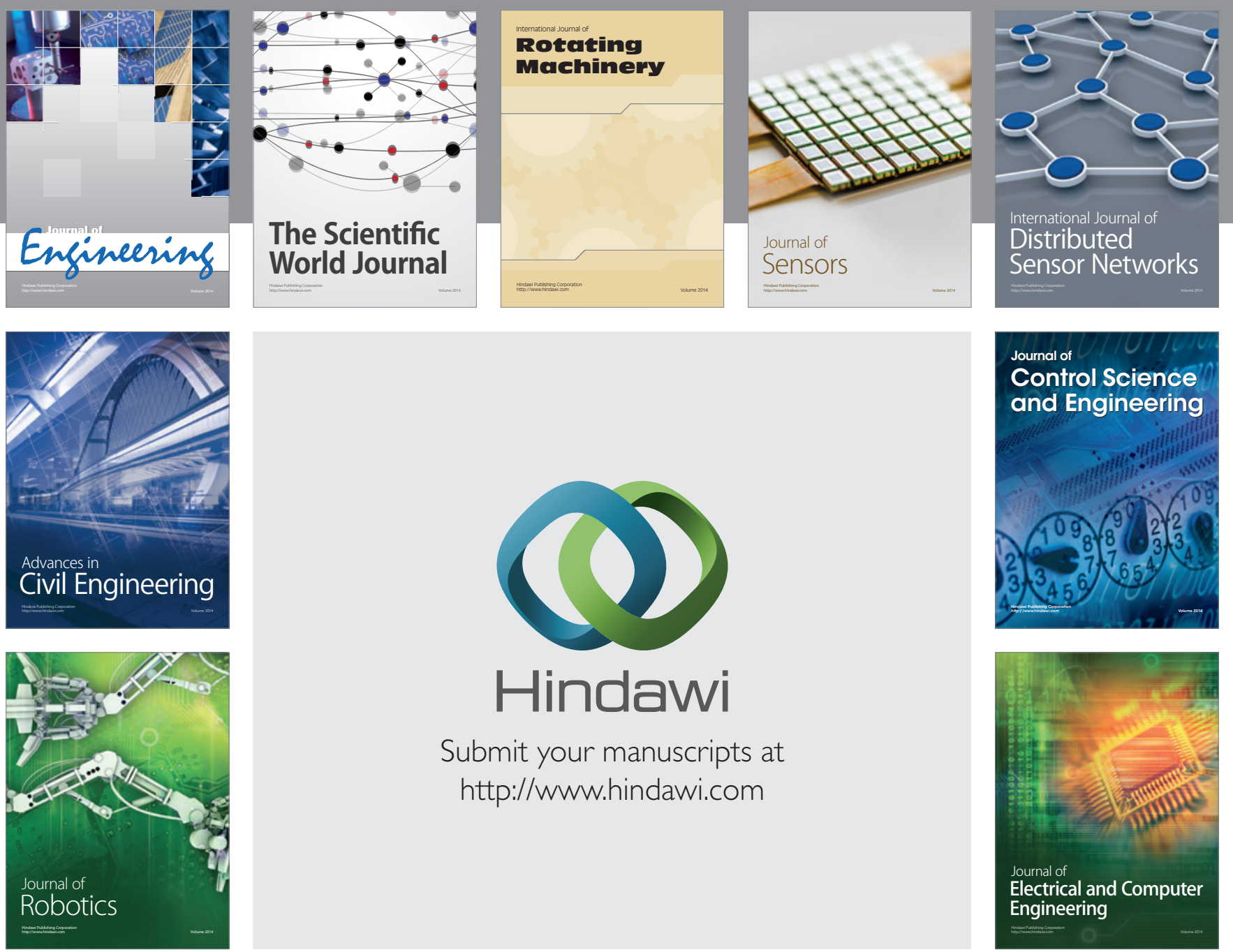

Submit your manuscripts at

http://www.hindawi.com
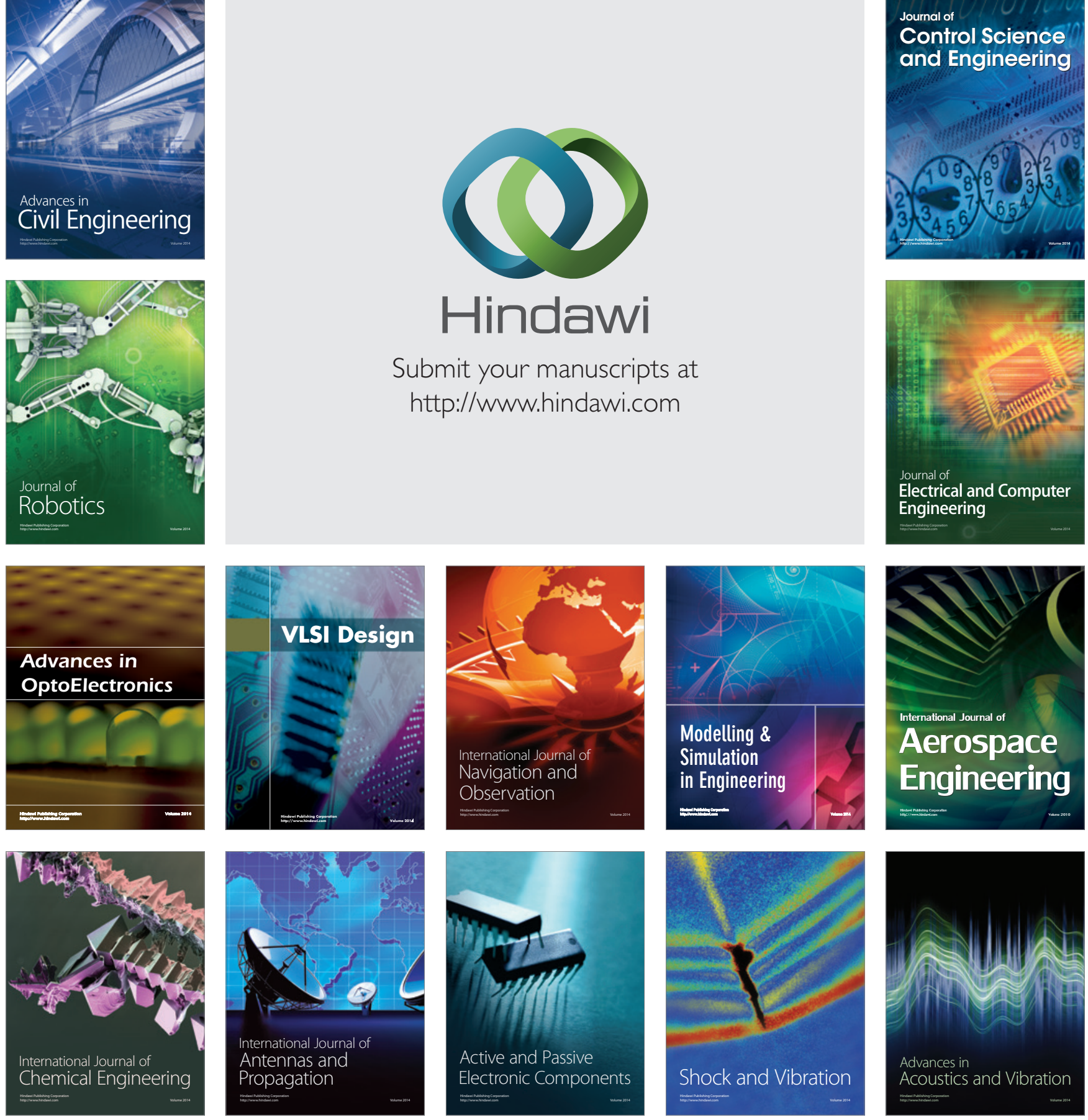